\title{
ADMINISTRACIÓN DE LA CALIDAD DE VIDA LABORAL EN PSICÓLOGOS EVALUADORES DE CENTROS DE RECONOCIMIENTO DE CONDUCTORES BOGOTÁ, COLOMBIA*
}

\section{ADMINISTRATION OF THE QUALITY OF WORK LIFE IN EVALUATING PSYCHOLOGISTS OF DRIVER RECOGNITION CENTERS BOGOTÁ, COLOMBIA}

Recibido: 25 de marzo de 2019

Evaluado: 12 de abril de 2019

Aprobado: 9 de mayo de 2019

\author{
Zaira Vanessa Andrade $\mathrm{Gil}^{*}$ \\ Universidad Europea del Atlántico \\ Orcid: 0000-0002-6754-4796
}

Cómo citar este artículo: Andrade Gil, Z. V. (2019). Administración de la calidad de vida laboral en psicólogos evaluadores de Centros de Reconocimiento de Conductores Bogotá, Colombia. Revista Estrategia Organizacional, 8 (2). pp. 145-178. doi: https://doi.org/10.22490/25392786.3435

* $\quad$ Artículo de investigación p del proyecto de investigación en el marco del programa de la maestría en Recursos Humanos y Gestión del Conocimiento de la Universidad Internacional Iberoamericana UNINI y la Universidad Europea del Atlántico UNEATLANTICO denominado "Calidad de vida laboral en Psicólogos Evaluadores de CRC Centros de Reconocimiento de Conductores en la ciudad de Bogotá, Colombia" con el apoyo de FUNIBER.

** Psicóloga, Tecnóloga en Multimedia egresada del SENA, Magíster en Recursos Humanos y Gestión del Conocimiento de la UNINI y la UNEATLANTICO. Actualmente cursa Especialización en Pedagogía en la Universidad del Tolima. Docente de la Institución Educativa Llanadas Municipio de Manzanares, Caldas.

Correo electrónico: zayita_12@hotmail.com 


\title{
RESUMEN
}

El presente artículo da a conocer los resultados de una investigación de tipo descriptivo y exploratorio en la que se brinda comprensión acerca de la Calidad de vida laboral en Psicólogos Evaluadores de Centros de Reconocimiento de Conductores (CRC) en la ciudad de Bogotá - Colombia, orientado a identificar desdelaperspectiva delos profesionaleslapercepción de satisfacción respecto a sucalidad de vida laboral en estas organizaciones. El trabajo investigativo se desarrolló con la participación de los psicólogos evaluadores que laboran en cuarenta y siete (47) CRC en la ciudad de Bogotá. Para ello se empleó como instrumento un cuestionario de datos sociodemográficos, la escala CVTGOHISALO y un guion y/o protocolo de entrevista. La interpretación de los datos se realizó a través del software especializado estadístico SPSS versión 20. Los resultados permitieron determinar que el nivel de calidad de vida global percibido por los Psicólogos Evaluadores es alarmante puesto que los profesionales se encuentran en riesgo en cinco (5) de las siete (7) dimensiones que componen la escala. Finalmente, se presenta una estrategia con el objetivo de proponer posibles soluciones que pudieran ser útiles tanto a los profesionales como a dichas organizaciones.

Palabras clave: calidad de vida, trabajo, administración, Centros de reconocimiento de conductores, psicólogos evaluadores.

\begin{abstract}
This article presents the results of a descriptive and exploratory research that provides insight into the Quality of work life in Psychologists Evaluators of Driver Recognition Centers (CRC) in the city of Bogotá - Colombia, oriented to identify from the perspective of professionals the perception of satisfaction with respect to their quality of work life in these organizations. The research work was developed with the participation of the evaluating psychologists who work in forty-seven (47) CRC in the city of Bogotá. For this purpose, a socio-demographic data questionnaire, the CVT-GOHISALO scale and a script and / or interview protocol were used. The interpretation of the data was done through the specialized statistical software SPSS version 20 . The results allowed to determine that the level of global quality of life perceived by the Evaluating Psychologists is alarming since the professionals are at risk in five (5) of the seven (7) dimensions that make up the scale. Finally, a strategy is presented with the aim of proposing possible solutions that could be useful both to professionals and to said organizations.
\end{abstract}

Keywords: Quality Of Life, Work, Administration, Driver Recognition Centers, Psychologists Evaluators. 


\section{INTRODUCCIÓN}

Existe consenso en afirmar que los funcionarios de la salud se desempeñan habitualmente en entornos caracterizados por una elevada carga laboral y desprovistas redes de apoyo social (Lee, Dai, Park y McCreary, 2013, citados por Pérez y Zurita, 2014). En este sentido, el caso de los Centros de reconocimiento de conductores (CRC) es interesante por ser entidades con objeto social diferente - cuentan con un registro especial de prestadores de servicios de salud- y tienen como propósito expedir de manera exclusiva, el Certificado de aptitud física, mental y de coordinación motriz para conducir. Lo anterior, mediante servicios de baja complejidad y consulta especializada (Resolución 0217 de 2014).

Aunque dicho procedimiento consta de la valoración del aspirante no sólo por parte de psicología, también de oftalmología u optometría, fonoaudiología y medicina general o interna; es necesario visibilizar la problemática que perciben los psicólogos evaluadores al interior de los CRC; quienes son parte fundamental de este proceso y tienen contacto con cientos de personas a las cuales se les verifican las aptitudes psicofísicas que se requieren para conducir un vehículo automotor.

En este escenario los psicólogos evaluadores tienen como objetivo valorar la aptitud de la capacidad mental y de coordinación motriz de los aspirantes: Trastornos mentales y de conducta, trastornos relacionados con sustancias, aptitud perceptivo-motora, y causas no especificadas. Todo ello implica excelente desenvolvimiento en cuanto a las normas que rigen el proceso, a los instrumentos, a las técnicas que se emplean y lo más importante, la presencia de competencias emocionales por parte del psicólogo; que no se encuentra exento de caer en la alienación, la insatisfacción, la mala voluntad, la reducción de la productividad, el ausentismo, la rotación, entre otros.

Asímismo, al emprender la consulta bibliográfica se encontró que hay muy pocas investigaciones sobre los CRC y las existentes no abordan las dificultades de los profesionales que laboran allí. Además, todo apunta a que las investigaciones sobre satisfacción de psicólogos en escenarios laborales son casi inexistentes y los estudios sobre calidad de vida laboral son muy pocos. De ahí que sea viable profundizar en el análisis de estos aspectos. 
Actualmente se sabe que el trabajo es el principal contribuyente al aumento de la calidad de vida de las personas; de esta manera, la calidad de vida laboral aumenta cuando se desempeña un rol que está acorde a las capacidades, la vocación y existen elementos que además promueven el crecimiento personal (González, et al., 2014). Es decir, el trabajo no es solamente una actividad económica, pues representa un espacio de desarrollo y desenvolvimiento que permite realizar aportaciones en beneficio de la sociedad (Patlán, 2016).

Por lo anterior, la investigación buscó ahondar en la problemática que perciben los psicólogos evaluadores en su contexto laboral y brindar estrategias que se puedan efectuar en los CRC; teniendo en cuenta que es deber de las organizaciones implementar acciones encaminadas a satisfacer la calidad de vida laboral (Patlán, 2016).

\section{SITUACIÓN OCUPACIONAL DE LOS PSICÓLOGOS EN COLOMBIA}

Dentro del gremio se afirma que la psicología se encuentra en "crisis". Esto se debe al alto número de universidades que ofertan dicha carrera (Cerca de sesenta y siete 67 instituciones de educación superior) y las bajas exigencias de ingreso. Según el observatorio laboral para la educación, hasta el año 2015 en Colombia se graduaron ochenta y cinco mil (85.000) psicólogos. Eso, sin contar que cada año el mercado laboral se "abarrota" con nuevas hojas de vida de recién egresados, por lo que en la actualidad las ofertas y condiciones laborales suelen ser lamentables, incluso llegando a ofrecer menos de un salario mínimo por los servicios profesionales.

Por otro lado, el libro Condiciones sociodemográficas, educativas, laborales y salariales del psicólogo colombiano producto de la investigación realizada por el Colegio Colombiano de Psicólogos COLPSIC (2010) "vuelve la mirada de los psicólogos sobre sí mismos" (p. 20) por lo que se ha convertido en un todo un hito gremial al contar con la participación de cuatro mil quinientos setenta y seis (4.576) profesionales.

Entre las consideraciones sobre las características de la muestra encuestada, se determinó que en general los psicólogos se encuentran en desventaja salarial y aunque se cree que el posgrado incrementa los ingresos la verdad es que el psicólogo nunca alcanza el nivel de vida de los demás profesionales. A su vez, para la mayoría de los egresados, en Colombia resulta una posibilidad lejana financiar estudios de posgrado o de un segundo idioma. 


\section{EL PAPEL DEL PSICÓLOGO EVALUADOR EN LOS CENTROS DE RECONOCIMIENTO DE CONDUCTORES (CRC)}

De acuerdo con el Informe Mundial sobre Seguridad Vial 2015 de la Organización Mundial de la Salud (OMS) anualmente mueren en accidentes de tráfico un millón doscientos cincuenta mil (1.250.000) personas. Es decir, cada día fallecen más de tres mil cuatrocientas diecisiete (3.417) personas en las vías. Para explicar por qué ocurren estos accidentes, se ha dicho que influyen tanto las condiciones de la vía como el estado de los vehículos; pero los estudios también sugieren la importancia del factor humano (Montoro, Carbonell y Tortosa, 1991; Carbonell, Montoro, Sanmartín y Tortosa, 1995; Montoro, Carbonell, Sanmartín y Tortosa, 1995; Montoro, Alonso, Esteban y Toledo, 2000; citados por Montoro, Roca y Tortosa, 2008)

Por esta razón estudiar los CRC es sumamente importante, pues allí se determina si un aspirante a obtener por primera vez, re categorizar y/o refrendar la licencia de conducción cumple con las exigencias para conducir un determinado vehículo. En este sentido, se habla de un proceso interdisciplinar que en ocasiones no se limita por la normativa, pues deja a criterio facultativo esta valoración (Ozcoidi, Sanz, Civera y Montoro, 2008).

Entretanto, desde el área de psicología, el proceso se constituye como una medida preventiva básica. También se debe mencionar que sobre los psicólogos evaluadores recae una gran responsabilidad respecto al control y la evaluación de los aspirantes que poseen "factores de riesgo asociados a los hábitos de conducta al conducir y su estado de salud" (Ozcoidi, et al., 2008).

Finalmente, existen pocos de estos centros en la ciudad de Bogotá (Cincuenta y cuatro certificados a la fecha). Así mismo, acceder a las ofertas laborales que ofrecen allí es difícil pues suelen ser limitadas, además hay conocimiento acerca de la alta rotación en estas organizaciones. En cuanto a la experiencia adquirida, suele ser demasiado específica para los psicólogos. Pese a que la problemática ya es conocida en el gremio, hasta el momento no se ha visibilizado.

\section{MATERIALES Y MÉTODOS}

La investigación corresponde a un diseño de tipo descriptivo y exploratorio, con un estudio transversal. Al respecto, se ha dicho que cuando el investigador construye un primer nivel de conocimiento exploratorio acerca de una temática, este proceso se puede complementar con el 
descriptivo. Según el problema y los objetivos planteados, en algunos estudios podrá establecerse su condición de exploratorio y descriptivo (Sampieri, Fernández y Baptista, 2010).

\section{POBLACIÓN Y MUESTRA}

En Colombia existen cerca de doscientos cincuenta y siete (257) CRC a nivel nacional. Sin embargo, esta investigación se centra en la capital del país. De igual forma, se dice que es necesario estudiar a todos los individuos de la población cuando es pequeña, como en este caso, por lo que se optó por realizar un estudio exhaustivo en los psicólogos evaluadores que laboran en los cincuenta y cuatro (54) CRC acreditados a la fecha en la ciudad de Bogotá por el Organismo nacional de acreditación ONAC.

Inicialmente se buscó evaluar el cien por ciento de la población. No obstante, al llevar a cabo la investigación sólo se pudo acceder a cuarenta y siete (47) de dichas empresas, contando con la participación de cincuenta y cuatro (54) psicólogos evaluadores (tabla 1).

Tabla 1. Resumen caracterización de los participantes.

\begin{tabular}{|c|c|c|c|c|c|}
\hline VARIABLE & \multicolumn{5}{|c|}{ PARTICIPANTES } \\
\hline Sexo & \multicolumn{2}{|c|}{$\begin{array}{c}\text { Femenino } \\
71 \%\end{array}$} & \multicolumn{3}{|c|}{$\begin{array}{c}\text { Masculino } \\
29 \%\end{array}$} \\
\hline Edad & $\begin{array}{c}\text { Hasta los } 25 \\
\text { Años } \\
16,3 \% \\
\end{array}$ & $\begin{array}{c}26-30 \text { Años } \\
30,9 \% \\
\end{array}$ & $\begin{array}{c}31-35 \text { Años } \\
30,9 \% \\
\end{array}$ & $\begin{array}{c}36-40 \\
\text { Años } \\
14,5 \%\end{array}$ & $\begin{array}{c}\text { Más de } 40 \text { Años } \\
7,2 \%\end{array}$ \\
\hline $\begin{array}{c}\text { Nivel } \\
\text { socioeconómico }\end{array}$ & \multicolumn{2}{|c|}{$\begin{array}{l}\text { Estrato II } \\
38,2 \%\end{array}$} & $\begin{array}{c}\text { Estrato III } \\
43,6 \%\end{array}$ & \multicolumn{2}{|c|}{$\begin{array}{c}\text { Estrato } I V \\
18,2 \%\end{array}$} \\
\hline $\begin{array}{l}\text { Antigüedad en el } \\
\text { cargo }\end{array}$ & $\begin{array}{c}1-12 \text { Meses } \\
33 \%\end{array}$ & $\begin{array}{c}13-24 \text { Meses } \\
34 \%\end{array}$ & $\begin{array}{c}25-36 \text { Meses } \\
13 \%\end{array}$ & Más & $\begin{array}{l}\text { e } 36 \text { Meses } \\
20 \%\end{array}$ \\
\hline $\begin{array}{l}\text { Antigūedad en } \\
\text { la empresa }\end{array}$ & $\begin{array}{c}1-12 \text { Meses } \\
50 \%\end{array}$ & $\begin{array}{c}13-24 \text { Meses } \\
29 \%\end{array}$ & $\begin{array}{c}25-36 \text { Meses } \\
9 \%\end{array}$ & Más & $\begin{array}{l}\text { e } 36 \text { Meses } \\
12 \%\end{array}$ \\
\hline $\begin{array}{l}\text { Vinculación } \\
\text { laboral }\end{array}$ & \multicolumn{2}{|c|}{$\begin{array}{c}\text { Contrato Laboral } \\
21,8 \% \\
\end{array}$} & $\begin{array}{c}\text { Prestación de } \\
\text { servicios } \\
76,3 \%\end{array}$ & & $\begin{array}{c}\text { Por dias } \\
1,8 \%\end{array}$ \\
\hline $\begin{array}{l}\text { Turno de } \\
\text { trabajo }\end{array}$ & \multicolumn{2}{|c|}{$\begin{array}{l}\text { Tiempo completo } \\
92,7 \%\end{array}$} & \multicolumn{3}{|c|}{$\begin{array}{c}\text { Medio Tiempo } \\
7,2 \%\end{array}$} \\
\hline $\begin{array}{l}\text { Actividades de } \\
\text { esparcimiento en } \\
\text { su tiempo libre }\end{array}$ & Si Realiza & $67 \%$ & \multicolumn{3}{|c|}{ No realiza } \\
\hline $\begin{array}{l}\text { Otro tipo de } \\
\text { actividad } \\
\text { remunerada }\end{array}$ & \multicolumn{2}{|c|}{ Si Realiza } & \multicolumn{3}{|c|}{ No Realiza } \\
\hline Estado civil & $\begin{array}{l}\text { Soltero } \\
54,6 \% \\
\end{array}$ & $\begin{array}{l}\text { Casado } \\
20 \%\end{array}$ & $\begin{array}{c}\text { Unión libre } \\
20\end{array}$ & & $\begin{array}{c}\text { Separado } \\
3,6 \%\end{array}$ \\
\hline Número de hijos & $\begin{array}{c}\text { Ninguno } \\
56,3 \%\end{array}$ & $\begin{array}{l}\text { Uno } \\
27,2 \%\end{array}$ & $\begin{array}{l}\text { Dos } \\
10,9\end{array}$ & & $\begin{array}{l}\text { Tres } \\
5,4 \%\end{array}$ \\
\hline Nivel educativo & \multicolumn{2}{|c|}{$\begin{array}{l}\text { Pregrado } \\
66 \%\end{array}$} & \multicolumn{3}{|c|}{$\begin{array}{c}\text { Especialización } \\
34 \%\end{array}$} \\
\hline
\end{tabular}

Fuente: elaboración propia 
Cabe señalar que la participación de los profesionales fue voluntaria, al momento de la aplicación se les dio a conocer los objetivos del estudio, la manera de diligenciar las escalas, el alcance del estudio y la confidencialidad de la información recolectada. En todos los casos se obtuvo el respectivo consentimiento informado.

Así mismo, González, et al., (2010) expresan que en la mayoría de investigaciones que abordan la calidad de vida laboral existen deficiencias en cuanto a la metodología empleada; así como inconvenientes en cuanto a la validez y la confiabilidad de los "métodos tradicionales de evaluación" entre los que se encuentran escalas y cuestionarios elaborados en otros contextos culturales y que aparentemente no poseen una adecuada adaptación lingüística y de contenido (Badia y Tuduela, 2003; citados por González, et al., 2010).

Respecto a la presente investigación, se parte de la propuesta conceptual que han elaborado González, Hidalgo, Salazar y Preciado:

La CVT es un concepto multidimensional que se integra cuando el trabajador, a través del empleo y bajo su propia percepción, ve cubiertas las siguientes necesidades personales: soporte institucional, seguridad e integración al puesto de trabajo y satisfacción por el mismo, identificando el bienestar conseguido a través de su actividad laboral y el desarrollo personal logrado, así como la administración de su tiempo libre. Implica la valoración objetiva y subjetiva de siete dimensiones, a saber: Soporte institucional para el trabajo, seguridad en el trabajo, integración al puesto de trabajo, satisfacción por el trabajo, bienestar logrado a través del trabajo, desarrollo personal. (González, et al., 2010, p.333).

\section{TÉCNICAS E INSTRUMENTOS}

Para la recolección de la información del presente estudio, se utilizaron como técnicas e instrumentos: Un cuestionario de datos sociodemográficos de elaboración propia y el instrumento CVT-GOHISALO (2009) elaborado por González, R., Hidalgo, G., Salazar, J.G., y Preciado, M. L; autores del Instituto de Investigación en Salud Ocupacional de Guadalajara, México; utilizado para la medición de la Calidad de vida de los trabajadores, siendo una herramienta versátil, confiable y válida de fácil administración. 


\section{ESCALA CVT-GOHISALO}

Para el estudio se eligió la escala de medición de Calidad de Vida en el Trabajo CVT-GOHISALO, debido a que posee validez de contenido, de constructo, de criterio y una alta fiabilidad con un Alfa de Cronbach de 0,952; midiendo lo que pretende medir. Muy pocos instrumentos para evaluar la calidad de vida laboral cumplen con estos criterios (González, et al., 2010). Además, la elaboración de la escala se sustentó bajo la teoría de la motivación de Maslow y la propuesta del Neopositivismo, destacando con criterios de objetividad y pertenencia (Pazos, 2014).

A su vez, CVT-GOHISALO está constituido por 74 ítems, que representan indicadores que integran las siete dimensiones que conforman la Calidad de vida laboral: Soporte institucional para el trabajo (SIT), Seguridad en el trabajo (ST), Integración al puesto de trabajo (IPT), Satisfacción por el trabajo (SPT), Bienestar logrado a través del trabajo (BAT), Desarrollo personal (DP) y Administración del tiempo libre (ATL). El análisis de cada una de las dimensiones facilita la comprensión de las personas y de los grupos.

Tabla 2. Puntuación T para calificar la escala CVT- GOHISALO.

\begin{tabular}{|c|c|c|c|c|c|c|c|}
\hline 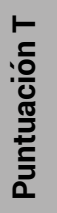 & $\begin{array}{c}\text { Soporte } \\
\text { Institucional } \\
\text { para el trabajo }\end{array}$ & $\begin{array}{c}\text { Seguridad } \\
\text { en el trabajo }\end{array}$ & $\begin{array}{l}\text { Integración } \\
\text { al puesto de } \\
\text { trabajo }\end{array}$ & $\begin{array}{l}\text { Satisfacción } \\
\text { por el trabajo }\end{array}$ & $\begin{array}{l}\text { Bienestar } \\
\text { logrado a } \\
\text { través del } \\
\text { trabajo }\end{array}$ & $\begin{array}{c}\text { Desarrollo } \\
\text { personal }\end{array}$ & $\begin{array}{c}\text { Administración } \\
\text { del tiempo } \\
\text { libre }\end{array}$ \\
\hline 99 & 56 & 58 & 40 & 44 & 44 & 32 & 20 \\
\hline 90 & 49 & 54 & 40 & 44 & 42 & 32 & 20 \\
\hline 80 & 45 & 48 & 38 & 42 & 41 & 30 & 19 \\
\hline 70 & 41 & 42 & 36 & 40 & 40 & 28 & 18 \\
\hline 60 & 37 & 36 & 34 & 38 & 39 & 26 & 17 \\
\hline 50 & 33 & 30 & 32 & 36 & 38 & 24 & 16 \\
\hline 40 & 29 & 24 & 30 & 34 & 37 & 22 & 15 \\
\hline 30 & 25 & 18 & 28 & 32 & 36 & 20 & 14 \\
\hline 20 & 21 & 12 & 26 & 30 & 35 & 18 & 13 \\
\hline 10 & 17 & 6 & 24 & 28 & 34 & 16 & 12 \\
\hline 1 & 4 & 5 & 8 & 5 & 23 & 8 & 3 \\
\hline
\end{tabular}

Fuente: Gonzáles et al., 2009, p. 49 
Tabla 3. Calidad de vida laboral de Psicólogos evaluadores que trabajan en CRC.

Fuente: Gonzáles et al., 2009, p. 49

https://doi.org/10.22490/issn.2539-2786

Estrategia Organizacional

Los puntajes pueden ser de tipo medio, o tener un valor por arriba o por debajo de la desviación típica. El puntaje obtenido se representa en valores T de McCall, allí el percentil 50 representa la ubicación media del puntaje bruto (Tabla 2). Un puntaje por debajo del valor T40 estaría en vulnerabilidad al riesgo del desequilibrio en la calidad de vida en el trabajo (González, et al., 2009). A partir de los resultados obtenidos se diseñó un guion y/o protocolo de entrevista para psicólogos evaluadores respecto a las dimensiones que puntuaron bajo en el instrumento CVT-GOHISALO, en busca de posibles soluciones.

\section{RESULTADOS}

La aplicación de la Escala CVT-GOHISALO permitió la obtención de una serie de hallazgos que determinaron las características de la calidad de vida laboral en Psicólogos Evaluadores que laboran en los centros de reconocimiento de conductores de la ciudad de Bogotá. Los resultados serán descritos y relacionados desde un punto de vista estadístico, gracias a la implementación del software especializado de estadística SPSS Versión 20.

\section{DIMENSIÓN SOPORTE INSTITUCIONAL PARA EL TRABAJO (SIT)}

Resultados medios en la dimensión de soporte institucional reflejan que los procesos de trabajo, la relación con los compañeros, la supervisión y el apoyo por parte de los superiores se perciben como elementos positivos. Al mismo tiempo, resultados altos reflejan que algunos profesionales están dispuestos a apropiarse en su rol y poseen sentido de pertenencia por la organización.

También se encontró que el 21 \% de los psicólogos evaluadores no consideran que su perfil profesional esté acorde a su puesto actual. Por ende, no perciben oportunidades de progreso, lo que puede desencadenar insatisfacción, dificultad en el desempeño de las funciones y tareas asignadas.

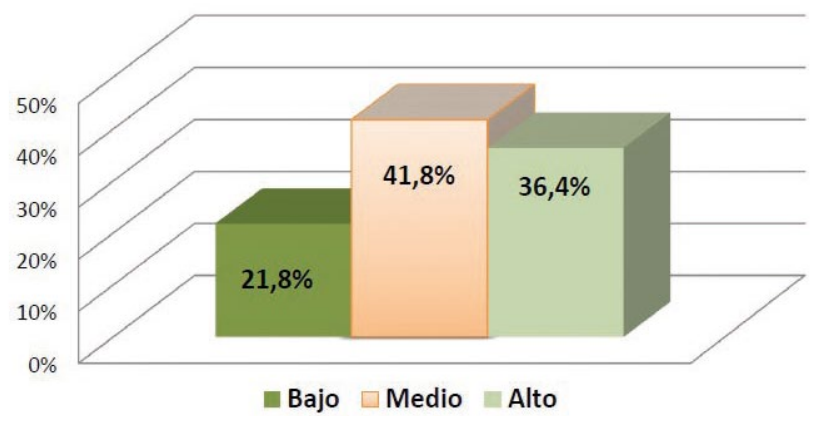

Figura 1. Soporte Institucional.

Fuente: elaboración propia 


\section{DIMENSIÓN SEGURIDAD EN EL TRABAJO (ST)}

Quienes puntuaron bajo en esta dimensión, perciben poca remuneración y reportan no tener satisfechas sus necesidades personales o los derechos contractuales. Sin embargo, cabe aclarar que la gran mayoría de los profesionales consideran que el cargo actual permite cubrir sus necesidades básicas y las de sus familias, lo que se traduce en mayor satisfacción frente a las condiciones del trabajo.

Con respecto al grado de satisfacción relacionado al salario que reciben, el $41 \%$ de los participantes no se encuentra satisfecho. Al mismo tiempo, el $55 \%$ de los profesionales expresó que las capacitaciones que reciben en estas organizaciones no resultan satisfactorias por lo que habría que emprender acciones frente a este aspecto.

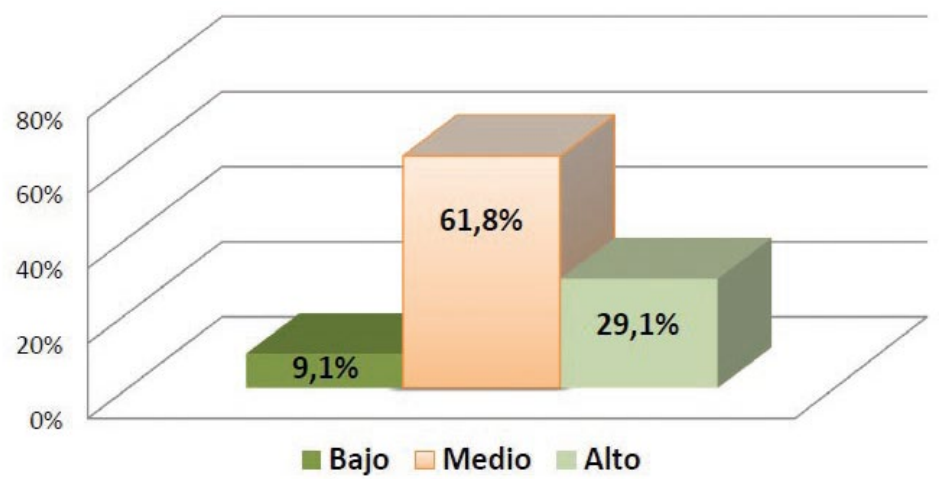

Figura 2. Seguridad en el trabajo.

Fuente: elaboración propia

\section{DIMENSIÓN INTEGRACIÓN AL PUESTO DE TRABAJO (IPT)}

En esta dimensión se encontró que más de la mitad de los participantes puntuaron bajo. Esto indica que los psicólogos evaluadores suelen expresar inconformidad con el cumplimiento de los objetivos institucionales, se desmotivan con facilidad.

Frente al ítem: "Considero que el puesto de trabajo que tengo asignado va de acuerdo con mi preparación académica y/o capacitación" el 50 \% expresó estar nada o poco de acuerdo, lo que resulta preocupante. En cuanto al grado de satisfacción respecto al trato con los compañeros de trabajo, los psicólogos perciben una alta satisfacción (89\%), pues ellos están prestos a colaborar cuando se presentan conflictos en el trabajo. 


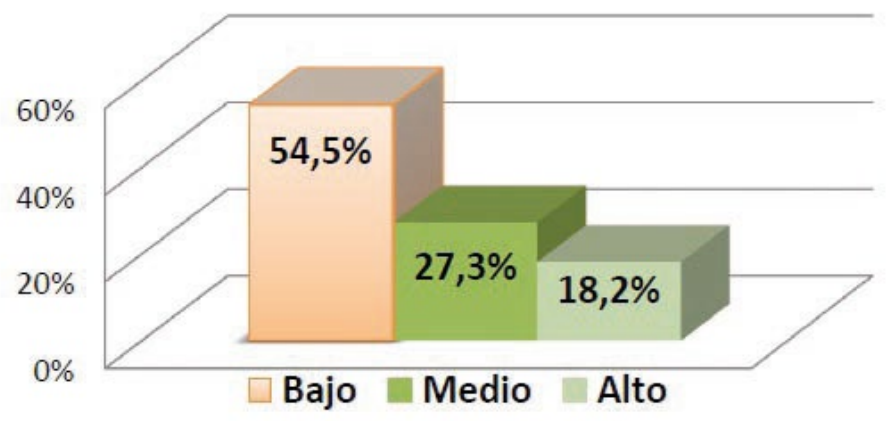

Figura 3. Integración al puesto de trabajo.

Fuente: elaboración propia

\section{DIMENSIÓN SATISFACCIÓN POR EL TRABAJO (SAT)}

Los participantes que puntuaron bajo se sienten insatisfechos por su actividad, los reconocimientos que reciben son escasos. Al mismo tiempo, la dedicación a sus labores es parcial.

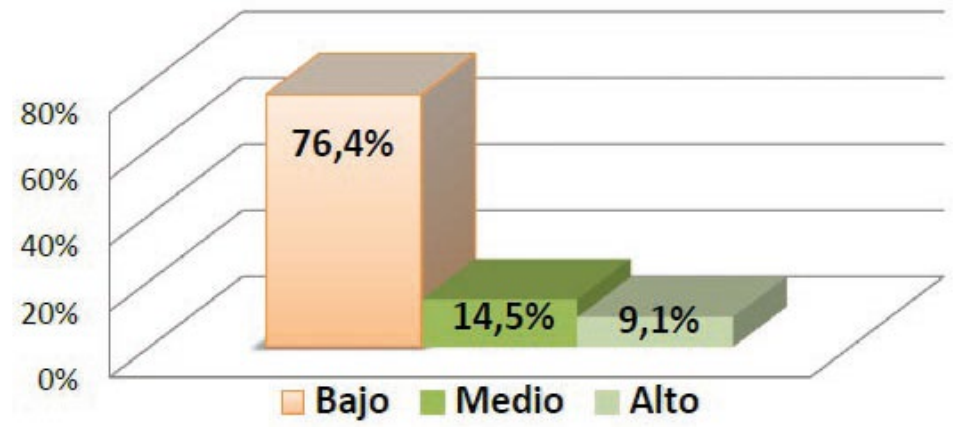

Figura 4. Satisfacción por el trabajo.

Fuente: elaboración propia

\section{DIMENSIÓN BIENESTAR LOGRADO A TRAVÉS DEL TRABAJO (BLT)}

Los profesionales puntuaron en el nivel bajo, lo que advierte riesgo en la salud física o emocional. Se denota insatisfacción con la remuneración adquirida por el trabajo y en consecuencia, responsabilizan al entorno laboral por su precariedad. No se sienten identificados con los objetivos de la institución; además, perciben que a ellos no se les hace justicia social. No obstante, quienes puntuaron medio y alto suelen estar satisfechos con el progreso personal, social y económico que han obtenido por su trabajo. 


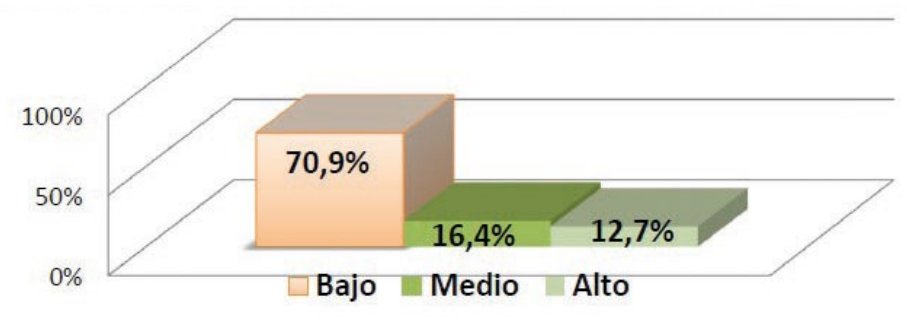

Figura 5. Bienestar logrado a través del trabajo.

Fuente: elaboración propia

\section{DIMENSIÓN DESARROLLO PERSONAL (DP)}

Los resultados apuntan a que los psicólogos evaluadores presentan nivel bajo en la dimensión desarrollo personal. Lo anterior expresa la inseguridad que ellos perciben por los logros alcanzados, se sienten vulnerables ante el trato con los usuarios y pueden considerar que el trabajo les ha disminuido su capacidad física o emocional. Todo ello conlleva a que sean pesimistas y en ocasiones oposicionistas ante los retos o metas institucionales. Lo anterior representa un alto nivel de riesgo en la insatisfacción personal.

Sin embargo, hay quienes obtuvieron un nivel medio y un nivel alto. Se trata de personas que mantienen su entusiasmo, un buen estado de ánimo, son optimistas y de trato amable en su trabajo. Estos últimos suelen tener metas claras, alcanzables y loables.

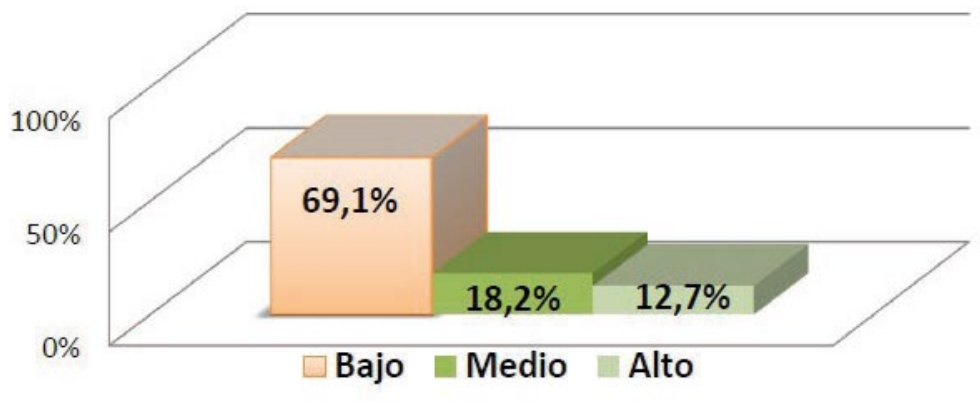

Figura 6. Desarrollo personal.

Fuente: elaboración propia 


\section{DIMENSIÓN ADMINISTRACIÓN DEL TIEMPO LIBRE}

El resultado en el nivel bajo se muestra en personas a quienes les falta una buena administración del tiempo, prolongan su jornada laboral o permiten que el trabajo repercuta en su descanso o recreación, esta dimensión advierte sobre el riesgo que puede existir con respecto a la parte nutricional e incluso emocional. Lo anterior puede parecer irónico por tratarse de profesionales en psicología, pero tal y como se ha advertido a lo largo de este artículo, en muchas ocasiones los psicólogos trabajan por y para los demás y sucede que se descuidan aspectos personales.

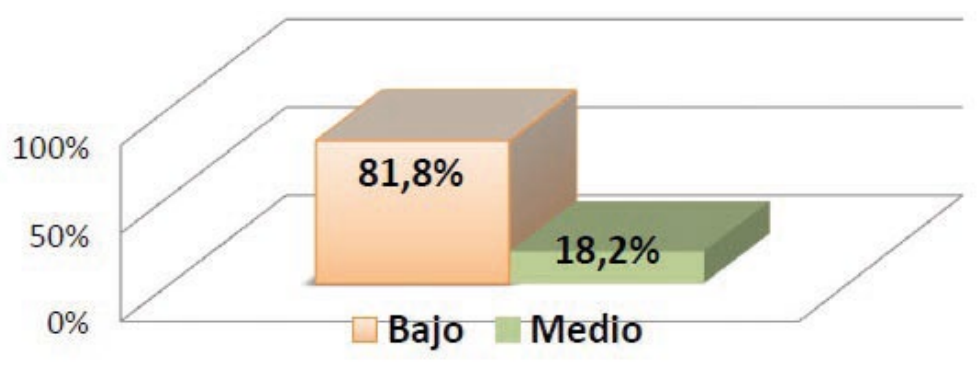

Figura 7. Administración del tiempo libre.

Fuente: elaboración propia

\section{RESULTADOS GLOBALES ESCALA CVT - GOHISALO}

De los resultados en el ámbito global, es preocupante que cinco (5) de las siete (7) dimensiones que comprenden la escala CVT-GOHISALO se encuentren en riesgo.

Tabla 3. Calidad de vida laboral de Psicólogos evaluadores que trabajan en CRC.

\begin{tabular}{|c|c|c|c|c|c|c|c|c|c|c|c|c|c|c|c|}
\hline \multirow{2}{*}{$\begin{array}{c}\text { Nivel de } \\
\text { satisfacción }\end{array}$} & \multirow{2}{*}{$\begin{array}{c}\text { Puntuación } \\
T\end{array}$} & \multicolumn{2}{|c|}{$\begin{array}{c}\text { Soporte } \\
\text { institucional } \\
\text { para el } \\
\text { trabajo }\end{array}$} & \multicolumn{2}{|c|}{$\begin{array}{l}\text { Seguridad } \\
\text { en el } \\
\text { trabajo }\end{array}$} & \multicolumn{2}{|c|}{$\begin{array}{l}\text { Integración } \\
\text { al puesto } \\
\text { de trabajo }\end{array}$} & \multicolumn{2}{|c|}{$\begin{array}{c}\text { Satisfacción } \\
\text { por el } \\
\text { trabajo }\end{array}$} & \multicolumn{2}{|c|}{$\begin{array}{c}\text { Bienestar } \\
\text { logrado a } \\
\text { través del } \\
\text { trabajo }\end{array}$} & \multicolumn{2}{|c|}{$\begin{array}{c}\text { Desarrollo } \\
\text { personal }\end{array}$} & \multicolumn{2}{|c|}{$\begin{array}{c}\text { Administración } \\
\text { del tiempo } \\
\text { libre }\end{array}$} \\
\hline & & $N$ & $\%$ & & $\%$ & $N$ & $\%$ & $N$ & $\%$ & $N$ & $\%$ & $N$ & $\%$ & $N$ & $\%$ \\
\hline & & 20 & 36,4 & 16 & 29,1 & 10 & 18,2 & 5 & 9,1 & 7 & 12,7 & 7 & 12,7 & 0 & 0 \\
\hline & & 23 & 41,8 & 34 & 61, & 15 & 27, & 8 & & 9 & 16,4 & 10 & 18,2 & 10 & 18,2 \\
\hline BAJO & $1-39$ & 12 & 21,8 & 5 & 9,1 & 30 & 54,5 & 42 & 76,4 & 39 & 70,9 & 38 & 69,1 & 45 & 81,8 \\
\hline
\end{tabular}

Fuente: elaboración propia 
Además, exhiben un nivel de satisfacción bajo frente a aspectos como: la remuneración, la relación entre perfil profesional - cargo actual, las capacitaciones que se brindan en la organización e, incluso, el trato con los usuarios. Al mismo tiempo, se manifiesta que hay pocos incentivos mientras que concurren las amonestaciones y sanciones. En ese sentido, los psicólogos evaluadores perciben que el trabajo puede conllevar a un riesgo en su salud física o emocional y se identifican muy poco con los objetivos organizacionales, además hay un bajo desarrollo en la esfera personal.

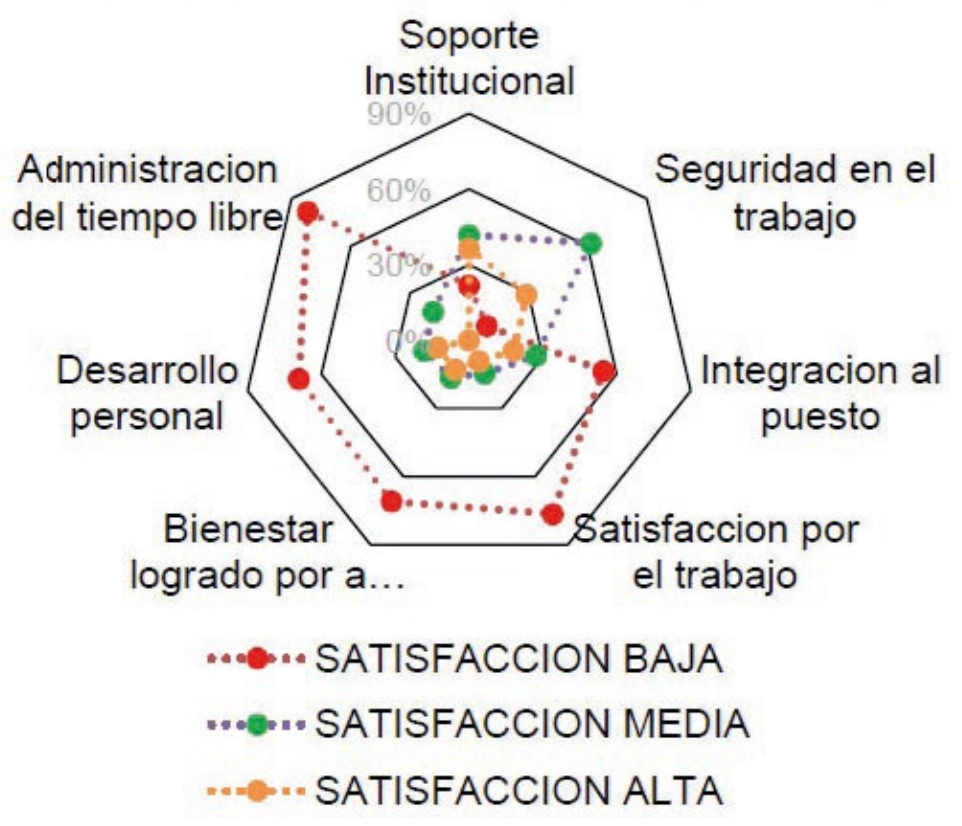

Figura 8. Resultados Globales Escala CVT - GOHISALO.

Fuente: elaboración propia

\section{RESULTADOS DE LAS ENTREVISTAS}

Los psicólogos evaluadores expresaron preocupación frente a la remuneración pues en algunos CRC no es acorde con las tablas salariales asignadas por el Colegio Colombiano de Psicólogos. Sumado a esto, el tipo de contrato suele ser por prestación de servicios, algo que genera inconformidad, especialmente porque los horarios suelen ser extensos, con jornadas laborales que, para algunos, van desde las siete de la mañana hasta las seis de la tarde y, todo lo anterior, pese a contar con un contrato de prestación de servicios, pues se les obliga a cumplir un horario. 
De igual forma, algunos profesionales expresaron haber sido víctimas de presiones por parte de los administradores de CRC para "pasar" o "dar por positiva la valoración de las aptitudes psicofísicas" a prácticamente todos los usuarios atendidos, porque de lo contrario se afectaban las ganancias de los CRC. En ocasiones esto conllevó a despidos y renuncias por parte de algunos colegas puesto que, como ya se mencionó, son múltiples los efectos negativos que se pueden suscitar de estas acciones desde distintos puntos de vista, especialmente desde la visión ética.

Más aún, debido a la gran cantidad de psicólogos en el mercado laboral, en estas organizaciones los profesionales perciben que son prescindibles ya que se conoce que algunos recién egresados estarían dispuestos a trabajar sin importar la remuneración económica o las condiciones impuestas. Así mismo, no hay claridad sobre la importancia del área de psicología en los CRC, razón por la cual, el ejercicio de la profesión pierde el sentido, se vuelve rutinario y mecánico.

En contexto general se cree que al cambiar el tipo de contrato podría mejorar la remuneración y, consecuentemente, se incrementaría la motivación. Algunos consideran, incluso, que estas organizaciones persiguen únicamente su bien económico; por lo cual, es indispensable que se valore y brinde oportunidades de desarrollo al recurso humano, el elemento más importante con el que cuenta cualquier empresa.

En cuanto al crecimiento personal en el puesto de trabajo, objetivos personales y objetivos organizacionales, la gran mayoría de los profesionales afirman la necesidad de contar con una capacitación al interior de los CRC, ya que solo se instruye acerca de la normatividad. Incluso, expresan no haber contado con un proceso de inducción, algo que influye negativamente en la percepción que tienen acerca del cargo de psicólogo evaluador.

Igualmente, se denota insatisfacción respecto a la administración del tiempo libre. Las jornadas extensas impiden gestionar el tiempo para estudiar, compartir otros espacios con familiares y amigos, entre otros. También están quienes afırman que lo más adecuado sería incluir actividades placenteras en el trabajo o que se dieran a conocer estrategias para afrontar el estrés y la fatiga. 


\section{DISCUSIÓN}

De acuerdo con los resultados obtenidos en el ejercicio investigativo, se conoció que el estado de la calidad de vida laboral de los psicólogos evaluadores que trabajan en CRC de la ciudad de Bogotá es realmente alarmante. En consecuencia, puntuaron bajo frente a cinco (5) de las siete (7) dimensiones que se abordaron desde la escala CVT-GOHISALO, a saber: Integración al puesto de trabajo, satisfacción por el trabajo, bienestar logrado a través del trabajo, desarrollo personal y administración del tiempo libre. Estos datos exhiben que los profesionales experimentan poca satisfacción respecto a su empleo, bajo sentido de pertenencia, escasa motivación e, incluso, poca identificación con las instituciones y sus objetivos.

Si bien es cierto que dos (2) de las dimensiones puntuaron en un nivel de satisfacción medio: Soporte institucional y Seguridad en el trabajo; tal y como mencionan Martínez, Oviedo y Luna (2015) se debe propender por la generación de empleos decentes, creativos, provechosos y seguros (Tabares y Vincos, 2015; García y Forero, 2016; Patlán, 2016).

Cabe destacar que al realizar la consulta bibliográfica no se hallaron investigaciones previas que abordaran la calidad de vida laboral de psicólogos y, mucho menos, acerca de psicólogos evaluadores que trabajan en CRC, por lo que se espera que todo lo aquí expuesto sea de gran utilidad para unir al gremio y guiar futuras investigaciones. El estudio permitió, además, conocer de primera mano la situación que se vive allí y también fue posible que se plantearan estrategias de solución frente a los niveles de satisfacción bajos en las dimensiones estudiadas.

Por otra parte, resulta interesante que, pese a la insatisfacción latente por parte de los profesionales, realmente son quienes más se encuentran interesados en realizar un cambio con respecto a su labor al interior de estas organizaciones. También les resulta imprescindible modificar la manera en la que son percibidos tanto por los usuarios como por los administradores, los profesionales de las diferentes áreas y las personas que integran estas entidades.

De igual forma, lo que se evidencia es que los psicólogos evaluadores desean crecer profesionalmente, realizar aportes significativos, aplicar sus conocimientos de manera profunda, enriquecer sus funciones y sus puestos de trabajo. La bibliografía menciona que si el trabajador no abandona un empleo es, o porque se aferra a la esperanza de corregir los elementos responsables 
de la insatisfacción, o porque no le queda otro remedio para no quedarse sin sustento. (Quintana, Paravic y Sáez 2015, pp. 58-59)

Así mismo, pese a que el trabajo va más allá de lo económico; pues, permite a las personas aumentar su potencial personal, aportar a la sociedad y desenvolverse en ella (Patlán, 2016); el salario también representa una gran preocupación para los psicólogos evaluadores y ello quedó registrado no sólo en los resultados de la escala, también en las entrevistas posteriores a la aplicación del instrumento. Los profesionales se ven atraídos por aquellas empresas que ofrecen mejor paga. Aquella retribución lleva implícito el prestigio, la autoestima, el reconocimiento y la estabilidad.

Por lo anterior, resulta oportuno que los administradores de estos centros busquen una remuneración justa y equitativa para los profesionales, concediéndole el valor que conlleva su cargo y de acuerdo al mercado laboral, pese a los factores internos y externos que pueden o no condicionar los salarios (Chiavenato, 2007).

De otro lado, como ya se mencionó en la caracterización de los participantes, la gran mayoría de psicólogos evaluadores se encuentra bajo un contrato de prestación de servicios (76,3\%). Al respecto, múltiples autores confirman que la contratación inestable genera efectos adversos en los trabajadores, afecta su satisfacción laboral, disminuye la calidad de vida laboral e implica condiciones de precariedad. También se ha descubierto que la manera en la que la empresa genera la relación de trabajo por medio del tipo del contrato, influye en la construcción de significados así como en el contrato psicológico por parte del empleado (Álvarez y Miles, 2006; Añez y Bonomie, 2007; Barattini, 2009; Benedito, Bonavia y Llinares, 2008; Contreras, Barbosa, Juárez, Uribe y Mejía, 2009; Gamero, 2007; Leguizamón y Gómez, 2001; Mañas, Salvador, Boada, González y Agulló, 2007; Martínez y Preciado, 2009; Segurado y Agulló, 2002; Tomás, Taboada y Toledo, 2004; Vega, Arévalo, Sandoval, Aguilar y Giraldo, 2006; citados por Uribe, Garrido y Rodrígruez 2011; Vesga, 2011).

Acerca de esto, se ha demostrado que quienes laboran bajo una contratación estable poseen mayor dominio de las políticas institucionales que quienes poseen otro tipo de contratación (Uribe, et al. 2011). De igual forma, en las entrevistas se relacionó claramente la motivación, el reconocimiento y la satisfacción al tipo de contrato laboral por no brindar suficientes garantías. 
Lo más adecuado sería analizar qué está sucediendo con ese tipo de contratos pues los profesionales se han pronunciado y han advertido que en ocasiones cumplen horarios (pese a que el contrato que se maneja es prestación de servicios) o se someten a largas jornadas sin recibir los beneficios que derivarían de las horas extras si tuvieran otra contratación. Tal es el caso de la cantidad de horas que se trabaja en algunos CRC, jornadas laborales de once horas, por ejemplo. A su vez, de acuerdo con la literatura, tras una gran cantidad de horas trabajadas subyace una exposición prolongada a los riesgos que pueden estar presentes en el ambiente laboral.

Por ello, se debate el hecho de que las nuevas formas de vinculación no generan la protección que se brindaba al trabajador hace algunos años (Uribe et al. 2011). En ese orden de ideas, las empresas olvidan que cuando se orientan hacia las personas suelen, como organización, ser mejor valoradas para laborar en ellas, pues se percibe que existe una primacía del ser humano antes que el capital.

Ahora bien, respecto a la preparación académica, sobresale el hecho de que los profesionales consideran que su capacitación no es acorde al cargo que desempeñan, y advierten que en sus funciones muy poco se aplica la "Psicología", lo que genera a su vez una gran insatisfacción y frustración. Sobre este punto, los investigadores afirman que a través del tiempo cada persona acumula experiencias en su lugar de trabajo y, es a partir de allí que, va consolidando una interpretación y un significado de su labor (Gracia, Martín, Rodríguez y Peiró, 2001; citados por Vesga, 2011).

Aunque se parte del hecho de que el trabajo permite que las personas sean "útiles" desempeñándose en algo que pueden realizar y para lo que cuentan con las condiciones propicias, contribuyendo a su vez a la sociedad (Parra, 2003); por parte de las empresas se debe propender por mejorar la experiencia del trabajador e intervenir para que las experiencias en la organización sean enriquecedoras.

Para ilustrar lo anterior, los psicólogos evaluadores formularon en las entrevistas no haber vivenciado nunca un verdadero proceso de inducción para laborar en los CRC. Por esta razón es de gran importancia generar un cambio respecto a la orientación del nuevo personal al interior de estas empresas. La inducción corresponde a las primeras impresiones que un empleado puede 
obtener, por eso resulta indispensable ya que incide en la productividad e incluso en la actitud hacia el trabajo (Siliceo, 2006). En efecto, si no se tiene claro la importancia que tiene el cargo, por qué es necesario emplear la psicología allí, la misión, los valores o la filosofía de la empresa, es muy difícil que los profesionales se identifiquen con estos y otros aspectos de la organización; realmente no van a sentirse parte del equipo ni van a comprometerse con su labor.

Al mismo tiempo, aunque los profesionales obtuvieron un nivel de satisfacción medio en las dimensiones de soporte institucional y seguridad en el trabajo; también expresaron la necesidad de actualizar sus conocimientos, habilidades y capacitarse no sólo referido a la norma que explicita los rangos de aprobación que debe tener un candidato desde el área de psicología, sino que se debe ir más allá. Chiavenato (2007) afirma que el capital humano de la organización puede valer más o menos en la medida en que la organización contenga personas que agreguen valor a la organización, dinamizándola e incrementando su competitividad.

No obstante, para ello se deben diagnosticar las necesidades de capacitación y desarrollo del personal, partiendo de la identificación de sus habilidades y deficiencias; se les debe ayudar a desarrollar sus capacidades brindando retroalimentación, tanto individual como grupal y facilitar el intercambio de experiencias a través del estudio de casos, por ejemplo (Siliceo, 2006).

En ese caso, los programas orientados al talento humano deben dirigirse a mejorar el bienestar de los equipos de trabajo, pues en las empresas de la actualidad es común que el ambiente laboral se caracterice por la presencia de variadas fuentes de estrés y situaciones que incitan a la inestabilidad e inseguridad en los miembros de la organización (Durán, 2010).

Así mismo, experiencias enriquecedoras como las que ha expuesto Montero, Asún, Estrada, Romero y Asún (2013) implementando un programa de Estiramientos sobre los niveles de ansiedad de los trabajadores de una plataforma logística que aumentó la vitalidad, la salud mental y redujo los niveles de ansiedad, dolor corporal y agotamiento en los participantes; pueden ser el punto de partida hacia nuevas prácticas que se podrían adaptar en los CRC. Este ejemplo expone que se pueden diseñar e implementar pequeñas acciones que no requieren un alto coste y generan un impacto tremendamente positivo. 
Sin embargo, la práctica de la actividad física es sólo un ejemplo, ya que empleando la imaginación aumentan las alternativas y las posibles acciones de mejora; además, se debe partir del contexto de cada organización. De igual forma, hay quienes debido al trabajo le restan horas al tiempo de descanso, al tiempo en familia, a los intereses individuales, a actividades sociales e intereses particulares (Parra, 2003). Lo anterior sin duda requiere atención por parte de los administradores de $\mathrm{CRC}$ pues es un factor que involucra a su vez el área emocional e incluso nutricional de las personas.

Tal y como expresa Maza (citado por Monesterolo, 2013) los trabajadores se encuentran dentro de un sistema que en ocasiones los obliga a desatender sus roles sociales y prácticamente corroe su tiempo libre. En otras palabras, se debe ahondar en estos aspectos pues la asignación del tiempo de trabajo, disponer de pausas y reposo puede incidir en el desempeño del trabajador, incurriendo no sólo en él sino también en el entorno y en la organización (Alautrey y Etxebarría, 2012; citados por Monesterolo, 2013). De esta manera, el ocio facilita la recuperación de la fatiga física y nerviosa, es un reparador que permite soportar las tensiones de las jornadas de trabajo (Román, 2006).

\section{CONCLUSIONES}

De los resultados, en forma global, es preocupante que cinco (5) de las siete (7) dimensiones que comprenden la escala CVT-GOHISALO se encuentren en riesgo puesto que exhiben un nivel de satisfacción bajo frente a aspectos como: la remuneración, la relación entre perfil profesional - cargo actual, las capacitaciones que se brindan en la organización e incluso el trato con los usuarios.

Por otra parte, las dimensiones que puntuaron en un nivel de satisfacción bajo son: Integración al puesto de trabajo, Satisfacción por el trabajo, bienestar logrado a través del trabajo, desarrollo personal y administración del tiempo libre. Estos resultados implican que los psicólogos evaluadores en general se sienten insatisfechos por su actividad, experimentan inseguridad frente a los logros alcanzados, se sienten vulnerables ante el trato con los usuarios. Incluso, hay quienes pueden considerar que el trabajo les ha disminuido su capacidad física o emocional. Esto último advierte un gran riesgo en la salud. 
Ahora bien, se obtuvieron resultados medios en la dimensión de soporte institucional, y en la dimensión seguridad en el trabajo, lo cual refleja que los procesos de trabajo, la relación con los compañeros, la supervisión y el apoyo por parte de los superiores se perciben en ocasiones como elementos positivos. Al mismo tiempo, algunos de los profesionales consideran que el cargo actual permite cubrir sus necesidades básicas y las de sus familias.

En cuanto al tipo de contrato, se determinó que la mayoría de profesionales poseen un contrato de prestación de servicios sometiéndose a largas jornadas de trabajo, cumpliendo horarios y siendo víctimas de presiones por parte de los administradores de CRC para valorar positivamente a prácticamente todos los usuarios atendidos respecto a las aptitudes psicofísicas, lo que en diferentes oportunidades conllevó a despidos y renuncias por parte de algunos psicólogos.

Referente al turno de trabajo se encontró que son muy pocas las organizaciones en las que los profesionales laboran medio tiempo. En cuanto a la antigüedad desempeñando el cargo de psicólogo evaluador (ya sea en la empresa actual o en otras anteriores) más de la mitad de los profesionales llevan entre uno y dos años laborando en CRC y existe una alta rotación por parte de los profesionales en estas organizaciones.

De otro lado, los reconocimientos que reciben los profesionales son escasos, por el contrario, se reciben amonestaciones o sanciones; por lo que creen que a ellos no se les hace justicia social. Suelen expresar inconformidad con el cumplimiento de los objetivos institucionales, se desmotivan con facilidad.

Sumado a esto, los psicólogos evaluadores carecen de una buena administración del tiempo, prolongan su jornada laboral o permiten que el trabajo repercuta en su descanso o recreación. Al respecto, vale la pena decir que quienes realizan actividades de esparcimiento en su tiempo libre perciben una mayor satisfacción en la dimensión soporte institucional para el trabajo, es decir, mayor apoyo por parte de su organización.

\section{RECOMENDACIONES}

Se recomienda a la comunidad académica concebir investigaciones e intervenciones que promuevan el bienestar y el mejoramiento continuo de la calidad de vida laboral del talento humano, 
especialmente en los psicólogos. Los estudios que se han llevado a cabo en torno a estos profesionales son escasos pero los resultados evidenciados en esta investigación muestran que es conveniente continuar profundizando en las condiciones laborales en las que ellos se encuentran, incluso en otras áreas de desempeño. Todo esto con el propósito de contribuir al ejercicio de la psicología en condiciones favorables que aporten al desarrollo personal, la satisfacción y el crecimiento profesional, visibilizando las problemáticas existentes.

Así mismo, es importante propiciar el sostenimiento de los lazos entre la academia y los profesionales, como soporte para el desarrollo continuo de las habilidades sociales, las habilidades para el trabajo, las competencias cognitivas, comportamentales y contextuales de los psicólogos y el mejoramiento de la calidad de vida laboral de los mismos.

Se sugiere a los profesionales en Psicología gestar proyectos tanto de investigación como de exploración tendientes a la comprensión y el fortalecimiento de la calidad de vida laboral, como un elemento fundamental del desarrollo integral en ambientes organizacionales.

Cabe mencionar que este estudio tuvo lugar pese a la negativa de algunos administradores de CRC, quienes no permitieron que los psicólogos evaluadores que allí laboraban participaran. Por ello, la invitación es que los resultados de esta investigación sean tomados en cuenta por parte de dichas organizaciones y se adelanten acciones, surjan programas en pro del mejoramiento de la calidad de vida laboral de los profesionales y que las estrategias aquí sugeridas se adapten a las necesidades de cada centro. Por esta razón, a continuación se expone una estrategia con el objetivo de hacer frente a las dificultades, con el deseo de que sea socializada y pueda ponerse en práctica.

\section{ESTRATEGIA MEJORANDO LA CALIDAD DE VIDA LABORAL EN PSICÓLOGOS EVALUADORES DE CRC}

Con el objetivo de identificar las posibles soluciones que pudieran ser útiles en las organizaciones frente a los resultados expuestos hasta el momento, se detallan a continuación propuestas que buscan el mejoramiento continuo de la organización respecto a elementos que en ocasiones son pasados por alto pero que en realidad son de suma importancia, tales como: La motivación, el reconocimiento, la satisfacción, la retribución y los incentivos, el crecimiento personal en el trabajo, entre otros. También se toman en cuenta las implicaciones prácticas que expuso Patlán 
(2016) quien asevera que las acciones para mejorar la calidad de vida laboral se deben enfocar a satisfacer las necesidades de los trabajadores.

Cabe resaltar que para la elaboración de las propuestas se contó con la participación de los psicólogos evaluadores, quienes se mostraron muy interesados en la elaboración de la estrategia. Con una posterior implementación son quienes se verían mayormente beneficiados y podrían convertirse en verdaderos gestores de cambio dentro de los CRC.

De igual forma, el mejoramiento de la calidad de vida laboral debe propiciar mayores oportunidades, equidad en el equipo de trabajo, equilibrio entre el trabajo y la vida familiar, comunicación asertiva, integración social, actividades que generen expectativas e incentiven, capacitación y formación (Tabares y Vincos, 2015). La estrategia establece los siguientes ejes de acción:
a. Adaptación laboral.
b. Carga mental de trabajo.
c. Motivación y satisfacción.

d. Reconocimiento en el trabajo e incentivos.

e. Objetivos de los trabajadores y objetivos organizacionales.

f. Administración del tiempo libre.

\begin{abstract}
a. Adaptación laboral
El proceso de adaptación laboral, a la organización y al entorno organizacional es fundamental pues no solo mejora la salud mental, también disminuye la alta rotación mientras aumenta la productividad y la satisfacción en los trabajadores. Tal y como expresa Porret (2014) es necesario llevar a cabo el erguimiento al talento humano, así como contar con un programa de acogida y llevar a cabo su ejecución. Este programa puede tener como objetivo: Dar a conocer la empresa -su historia, su actividad, su organización, valores-, dar a conocer a el equipo de trabajo - superiores,
\end{abstract}


compañeros, colaboradores inmediatos, líderes-, dar a conocer los aspectos productivos de la compañía -exponer la actividad o rendimiento, los sistemas de incentivos-, dar a conocer los aspectos sociales - derechos y deberes, reglamentos, horarios-.

Lo anterior busca que se logre una adecuada adaptación laboral implementando acciones frente a factores cognitivos -interpretación de la información relevante en el puesto de trabajo, carga mental y toma de decisiones-, factores físicos y biológicos - posturas, manipulación de objetos, movimientos repetitivos, disposición espacial del puesto- y factores sociales -comunicación, horarios y turnos, estructuras organizativas, cultura de la organización-. Como la adaptación varía de una persona a otra y puede variar de un momento a otro en un mismo individuo es importante que dichas acciones se realicen constantemente (Calle, 2011).

Algunos autores han establecido como recomendación para el proceso de adaptación laboral (Calle, 2011):

- Realizar un programa de inducción completo que incluya la información de la organización (Historia, misión, visión, políticas, filosofía, valores, reglamento interno, entre otros).

- Brindar información del cargo al profesional (Énfasis en la importancia del cargo para la organización).

- Presentación de los compañeros de trabajo y jefes.

- Entrega del manual de funciones y del manual de procedimientos.

- Generar un ambiente de respeto y sana convivencia, donde la comunicación sea efectiva entre jefes, jefes-subalternos y compañeros del mismo nivel, las normas sean claras, se respeten las jerarquías y conductos regulares.

- Los trabajadores deben conocer sus funciones, derechos y responsabilidades.

- El bienestar y la seguridad de todos los trabajadores debe ser una prioridad para la organización. 
b. Carga mental de trabajo

Si tomamos algún referente exitoso existente en el mercado laboral colombiano, resalta la gestión del talento humano adelantada por el Grupo Nutresa. Esta compañía ha expresado que sus fortalezas como mejor empleador son: Proyección de crecimiento y carrera, equilibrio entre la vida personal y laboral, salarios y beneficios, valores éticos y calidad del liderazgo (Nutresa, 2013). De esta manera, las empresas que se orientan hacia las personas suelen ser mejor valoradas para laborar en ellas, pues se percibe que existe una primacía del ser humano antes que el capital. En el caso de los CRC es indispensable comenzar a ejecutar acciones en las que analicen las exigencias del trabajo al que se están sometiendo los psicólogos evaluadores y así contrarrestar sus efectos negativos.

A su vez, la carga mental de trabajo se concibe como los requerimientos psicofísicos a los que se somete al trabajador a lo largo de su jornada y se parte tanto de las características de la persona como de las exigencias del trabajo. En el caso de los psicólogos evaluadores, muchos reportaron aburrimiento y monotonía producidos por su trabajo, que según ellos requieren poco contenido mental o intelectual. Las situaciones de subcarga mental pueden resultar nocivas para los profesionales pues el trabajo debe plantear ciertas exigencias mentales, de lo contrario mana un empobrecimiento de la inteligencia (Sebastián y del hoyo, 2002). Al mismo tiempo, el desarrollo de las funciones se caracteriza por un apremio constante de tiempo, se exige rapidez a la hora de tomar elecciones y se debe mantener la atención a lo largo de todo el proceso, pese a que es monótono.

\section{Las propuestas son:}

- Implementación de pausas activas.

- Entrenamiento en las labores propias del cargo.

- Introducir pausas para analizar el momento actual (Técnicas para combatir el estrés).

- Enriquecimiento de las tareas con elementos cognitivos (Se puede contar con la retroalimentación constante por parte de los superiores acerca de los aspectos que se pueden mejorar, cambiar u optimizar en el desempeño del rol del psicólogo evaluador sin que ello suponga mayor presión). 
- Ampliación de las tareas (Se ha dicho que se requiere ampliar la parte de psicología, cada psicólogo podría diseñar un guion de preguntas para ampliar la información acerca del candidato y conocer aún más las características de la personalidad, antecedentes, entre otros, del usuario en cuestión)

- Evitar la presión sobre los retrasos.

c. Motivación y satisfacción

Patlán (2016) expresa que las acciones para mejorar la calidad de vida laboral se deben enfocar a satisfacer las necesidades de los trabajadores. De acuerdo con Tabares y Vincos (2015) el papel del reconocimiento personal es de suma relevancia ya que se encuentra inmerso en las necesidades de estima o aprecio que describe la pirámide de necesidades de Maslow, además se le ha relacionado con la mejora del bienestar, la satisfacción laboral, la productividad y el desempeño.

Por su parte, la motivación se define como un proceso que impulsa, guía, dinamiza y mantiene el comportamiento de las personas para que puedan realizar y alcanzar los objetivos esperados dentro de la organización. Una vez se ha reconocido la importancia del manejo de la motivación se puede lograr que sus miembros experimenten una mayor satisfacción y a su vez que la organización obtenga mejores resultados. En cuanto a la satisfacción, se le define como una actitud que incide en la motivación y depende del grado de concordancia entre lo que una persona busca en su trabajo y en lo que este le reporta en la realidad (Ramirez, Abreu y Badii, 2008).

\section{Las propuestas son:}

- En lo posible, igualar los sueldos del mercado.

- Aumentar la seguridad laboral o grado del trabajador sobre su continuidad en el empleo.

- Brindar capacitaciones mes a mes que busquen mejorar la comunicación, el bienestar, el clima y la cultura laboral, entre otros temas (Implicar a todo el personal). 
- Contemplar la elaboración de un plan de formación al talento humano mes a mes (En estas reuniones se pueden realizar diversas actividades, de retribución e incentivos).

- Facilitar espacios para que se den intercambios de ideas constructivas respecto a la organización o sus labores en la institución y para que se sientan tomados en cuenta.

- Analizar cómo se está manejando el horario laboral, pues las personas suelen preferir horarios compatibles con actividades que faciliten su vida personal.

De igual forma, el ambiente social debe convertirse en un facilitador de la motivación

- Interesar a los trabajadores por la consecución de los logros y capacitarlos para que presten un mejor servicio.

- Hacer énfasis en la importancia de las funciones para el contexto organizacional y social.

- Brindar y apoyar la autonomía, esto suele aumentar la autoestima y la autorrealización.

- Eliminar cualquier tipo de riesgo físico, pues los trabajadores valoran las condiciones físicas óptimas de trabajo.

d. Reconocimiento en el trabajo e incentivos

Está demostrado que cuando se estimula el desarrollo personal y el reconocimiento personal se impulsa el crecimiento del trabajador y, a su vez, el de la organización (Tabares y Vincos, 2015). Hernández y Vergara (2013) afirman que las compensaciones que no son en efectivo han tomado mayor importancia para atraer y retener al personal. Entre las compensaciones que van más allá del efectivo mencionan: Seguros médicos, programa de asistencia legal, guardería para los hijos de los empleados, días pagados por enfermedad, maternidad o muerte; programa de asistencia para la salud y empleo, ayuda para pagos de colegiatura, seguridad social, entre otros.

Al respecto, Garza (2000) expresa que cada organización debe analizar qué compensaciones puede brindar teniendo en cuenta su contexto, partiendo de la oferta y demanda, sindicatos, 
capacidad de pago, productividad y legislación gubernamental, entre otros. Finalmente, al reconocer el trabajo se refuerza el compromiso del empleado con la organización, una vez se han establecido metas y estas se han alcanzado es posible implementar incentivos, ya sean por equipo o por área. Se debe dar a entender que las personas son miembros de un equipo y que cada integrante es de gran importancia.

Las propuestas son:

- Establecer metas para alcanzar con plazos mensuales, esto representaría todo un reto para los profesionales.

- Brindar reconocimiento público (e incluso económico) para quienes logren las metas propuestas, de esta manera se fomentaría la sana competencia para brindar un mejor servicio.

- Analizar de qué manera se están brindando incentivos o beneficios económicos o cómo se pueden incluir en la organización.

- En las reuniones mensuales decidir con el equipo de profesionales qué metas se van a establecer, se deben tratar las metas o fracasos del mes anterior, así aumentará el compromiso con la institución por parte de los trabajadores - sin que ello suponga que todos los aspirantes deben aprobar la valoración psicofísica, ni que se condicione el ejercicio profesional-.

e. E. Objetivos de los trabajadores y objetivos organizacionales

Las instituciones y compañías se deben fijar como objetivo el potencializar las capacidades particulares, ampliar la seguridad en el trabajo y las oportunidades de ascenso (González, Hidalgo y Salazar, 2007). Entre los casos de empresas exitosas se había detallado el de Colgate - Palmolive México (2015 citado por Patlán, 2016) sus programas buscan estimular la carrera laboral a través de la capacitación, la educación, el crecimiento personal, la inclusión, la participación, el equilibrio entre el trabajo y la vida personal, un ambiente laboral motivador, reconocimiento, recompensas, valores como: el respeto, el trabajo en equipo y la mejora continua; esta organización cuenta con programas como el de gestión con respeto, desarrollo profesional, remuneración por el desempeño, entre otros. 
En este sentido, lo que se puede analizar del ejemplo anterior es que se debe buscar que el ambiente laboral facilite la consecución de las metas personales de cada trabajador. Ello no sólo aumentará el compromiso hacia la institución, sino que se percibirá que a través del cumplimiento de las metas organizacionales también es posible que los empleados se vean beneficiados (Almonacid, 2013). Además, existe una relación directa entre los resultados empresariales y el compromiso por parte de los trabajadores (Granados, 2011). Finalmente, tal y como expresa Siliceo (2006) resulta indispensable diagnosticar las necesidades de capacitación y desarrollo, brindando retroalimentación individual y grupal; de esta manera se podrá propiciar el intercambio de experiencias y se generará mayor valor en la organización.

\section{La propuesta comprende:}

- Incentivar a la capacitación.

- Brindar apoyo cuando el profesional requiera estudiar.

- Las empresas pueden apoyarse en programas gubernamentales que aportan fondos para la capacitación de los trabajadores.

f. F. Administración del tiempo libre

De acuerdo con diversos autores implementar acciones y proyectos relacionados con la calidad de vida laboral resulta positivo tanto para las empresas como para el talento humano (Granados, 2011; Hernández, Vergara y Peña 2013; Nutresa, 2013; Dirección de Comunicaciones Corporativas, Grupo Bancolombia, 2015; Libien, 2016; Patlán, 2016; Revista Dinero, 2017; Borda, 2017.) En el caso de Bancolombia, por ejemplo, como organización ha llevado a cabo esfuerzos en materia de bienestar, calidad de vida y felicidad (Dirección de Comunicaciones Corporativas, Grupo Bancolombia).

En este sentido, la administración del tiempo libre también podría ser un tema interesante para discutir con los profesionales, pues se trata de la dedicación que le están brindando a realizar otras actividades, en otros espacios y que son igual de significativos. 
Por ello, el descanso resulta fundamental para recargar energía, cambiar de actitud y trabajar con un ánimo diferente. Por último, cabe mencionar que diversos autores y compañías resaltan la importancia de lograr que el trabajador maneje un equilibrio entre la vida personal y laboral.

\section{La propuesta implica:}

- Brindar herramientas que permitan mejorar la gestión del tiempo por parte de los profesionales, realmente ellos agradecerán el hecho de que se les ofrezca una orientación que vaya más allá de las capacitaciones cotidianas.

\section{AGRADECIMIENTOS}

A FUNIBER, la fundación que me otorgó la beca para realizar el posgrado, sin la que nada de esto hubiera sido posible. A la Doctora Sonia Juliana Pérez Pérez por su acompañamiento en este proceso. A todos los psicólogos evaluadores que decidieron voluntariamente participar en este estudio, así como a las organizaciones que me abrieron sus puertas. A mi familia por ser el motor de mi vida. A todas aquellas personas que de una u otra forma con sus palabras, consejos y acciones me han animado a continuar luchando por mis sueños.

\section{REFERENCIAS}

Almonacid, M. J. S. (2013). Propuestas de intervención en la rotación de personal en la empresa Cruz del Sur, orientado a los cargos de Conductores y Auxiliares de buses interurbanos. (s.d.).

Borda, J. (2017). Google es la empresa de los sueños de los colombianos, ¿Por qué? Recuperado de: http://www.elempleo.com/co/noticias/mundo-empresarial/google-es-la-empresa-de-lossuenos-de-los-colombianos-por-que-5434.

Calle, O. V. (2011). Adaptación laboral: Factor clave para el rendimiento y la satisfacción en el trabajo. Cultura educación y sociedad, 2(1).

Chiavenato, I. (2007). Administración de recursos humanos, el capital humano de las organizaciones. São Paulo: Mac Graw Hill.2000. 
Colegio Colombiano de Psicólogos, COLPSIC. (2010). Condiciones sociodemográficas, educativas, laborales y salariales del psicólogo colombiano. Recuperado de: http://www. colegiocolombianodepsicologos. org/documentos/condiciones_del_psicologo. Pdf

Dirección deComunicaciones Corporativas, GrupoBancolombia.(2015). Bancolombia,laempresaprivada con el mejor talento humano del país según Merco. Recuperado de: https://www.grupobancolombia. com/wps/portal/acerca-de/sala-prensa/todos-los-articulos/responsabilidad-social-ambiental/ bancolombia-la-empresa-privada-con-el-mejor-talento-humano-del-pais-segun-merco.

Durán, M. M. (2010). Bienestar psicológico: el estrés y la calidad de vida en el contexto laboral. Revista nacional de administración, 1(1), 71-84.

García, M. y Forero, C. (2016). Calidad de vida laboral y la disposición al cambio organizacional en funcionarios de empresas de la ciudad de Bogotá-Colombia. Acta Colombiana de Psicología, 19(1).

Garza, J. (2000). Administración contemporánea. México: Mc Graw Hill.

González, R., Hidalgo, G. y Salazar, J. (2007). Calidad de vida en el trabajo: un término de moda con problemas de conceptuación. Psicología y salud, 17(1), 115-123.

González, R., Hidalgo, G., Salazar, J. y Preciado, M. (2009). Instrumento para medir la Calidad de Vida en el Trabajo CVT-GOHISALO, manual para medir su aplicación e interpretación. Instituto de Investigación en Salud Ocupacional. Guadalajara. México: Ediciones de la Noche.

González, R., Hidalgo, G., Salazar, J. G. y Preciado, M. L. (2010). Elaboración y validez del instrumento para medir calidad de vida en el trabajo" CVT-GOHISALO. Ciencia y Trabajo, 12, 332-340.

Granados, I. (2011). Calidad de vida laboral: historia, dimensiones y beneficios. Revista de Investigación en Psicología, 14(2), 209-221.

Hernández Trujillo, D. M., Vergara Gómez, C. P. y Peña Carrillo, A. D. (2013). Análisis del modelo de gestión humana de Bancolombia Cartagena. (Tesis). Cartagena, Colombia. 
Libien, S. (2016). Calidad de Vida en el trabajo en profesores de tiempo completo de la facultad de medicina de la universidad autónoma del estado de méxico. Revista acta educativa. Recuperado de: http://www.universidadabierta.edu.mx/ActaEducativa/descripcion.php?papeiden=53.

Martinez, L., Oviedo, O. y Luna, C. (2015). Impacto de las condiciones de trabajo en calidad de vida laboral: Caso del sector manufacturero de la Región Caribe colombiana. DYNA, 82(194), 194- 203.

Ministerio de Transporte. (2014). Resolución 0217 de 2014. Colombia.

Monesterolo de Ramírez, G. (2013). Jornadas laborales prolongadas y sus repercusiones en el buen vivir del trabajador y de su familia (Tema Central). (s.d.)

Nutresa, G. (2013). Informe anual y de sostenibilidad 2012. Medellín. Recuperado de: 2017.

Román, G. M. (2006). El tiempo libre y ocio reivindicado por los trabajadores. PASOS. Revista de Turismo y Patrimonio Cultural, 4(3), 301-326.

Montero, J., Asún, S., Estrada, N., Romero, R. y Asún, R. (2013). Efectividad de un programa de estiramientos sobre los niveles de ansiedad de los trabajadores de una plataforma logística: un estudio controlado aleatorizado. Atención Primaria, 45(7), 376-383.

Montoro González, L., Roca Ruiz, J. y Tortosa Gil, F. (2008). Influencia del permiso de conducción por puntos en el comportamiento al volante: percepción de los conductores. Psicothema, 20(4).

Ozcoidi, M., Sanz, M. R., Civera, C. y Montoro, L. (2008). Valoración de la aptitud psicomotora y la inteligencia requerida para conducir en los Centros de Reconocimiento de Conductores. Psychosocial Intervention, 17(1), 23-32.

Organización Mundial de la Salud. (2015). Global status report on road safety 2015. (s.d.)

Parra, M. (2003). Conceptos básicos en salud laboral. Santiago de chile: Oficina internacional del trabajo, OIT. 
Patlán Pérez, J. (2016). Derechos laborales: una mirada al derecho a la calidad de vida en el trabajo. Ciencia Ergo Sum, 23(2).

Pazos, A. (2014). Calidad de vida laboral de un grupo de personas en situación de Discapacidad Cali 2013. Universidad del Valle, Colombia.

Pérez, D. y Zurita, R. (2014). Calidad de vida laboral en trabajadores de salud pública en Chile. Salud y Sociedad, 5(2), 172-180.

Porret. M. (2014). Gestión de Personas. Manual para la Gestión del Capital Humano en las Organizaciones. Esic Editorial.

Quintana, M. O., Paravic, T. y Sáez, K. (2015). Calidad de vida en el trabajo percibida según niveles de atención y categorías de enfermeras. Ciencia y enfermería, 21(3), 49-62.

Revista Dinero. (2017). Las empresas colombianas con mejor reputación corporativa en 2017. Recuperado de: http://www.dinero.com/edicion-impresa/negocios/articulo/monitor-empresarialde-reputacion-corporativa-merco-2017/251533.

Sampieri, R., Fernández, C. y Baptista, L. (2010). Metodología de la investigación. México: McGraw-Hill.

Sebastián García, O. y Del Hoyo Delgado, M. (2002). La carga mental de trabajo. [Informe] Madrid, España: Instituto Nacional de Seguridad e Higiene en el trabajo.

Ramírez, R., Abreu, J. L. y Badii, M. H. (2008). La motivación laboral, factor fundamental para el logro de objetivos organizacionales: Caso empresa manufacturera de tubería de acero. Revista Daena (International Journal of Good Conscience), 3(1).

Siliceo, A. (2006). Capacitación y desarrollo de personal. Editorial Limusa. 
Tabares Alzate, D. M. y Vincos Basto, A. I. (2015). Calidad de vida laboral del grupo de empleados de la Fundación Centro Internacional de Estudios Avanzados en Niñez y Juventud CINDE-Sede Manizales. (s.d.)

Uribe-Rodríguez, A. F., Garrido-Pinzón, J. y Rodríguez, A. M. (2011). Influencia del tipo de contratación en la calidad de vida laboral: manifestaciones del capitalismo organizacional. Revista Virtual Universidad Católica del Norte, 33.

Vesga Rodríguez, J. J. (2011). Los tipos de contratación laboral y sus implicaciones en el contrato psicológico. Pensamiento psicológico, 9(16), 171-182. 